\title{
PROJECT MANAGEMENT - THEN AND NOW
}

\author{
Diana Elena Ranf ${ }^{1}$
}

\begin{abstract}
The article analyzes the strategic importance of the project management, that ability of managers to manage projects consistently and competently, being considered a strategic competence. It is also analysed the change of project management vision in terms of the manager's role and responsibility, the necessary knowledge, the clients' expectations and the definition of success. The article underlines the fact that managers begin to focus more and more on business. Projects should now be regarded from a strategic perspective, in the context of a business or an enterprise that should provide value both to the client and to the parent corporation.
\end{abstract}

Keywords: strategic, competences, management, project, changes.

JEL codes: $M 16$

\section{Introduction}

This article brings forward changes, current trends in project management. This evolution of the concept of project management and projects took place amid economic changes that dominated environment and society in general.

Project management was provided by renowned authors, experts in managing projects, such as E. Verzuh, D. Lock, J. Turner, R. Newton, G. Hofstede, G. Heerkens, H . Kerzner, S. Portny, E. Marmel, K. Conay. Romanian specialists in project management include: A. Bârgăoanu, D. Dumitrascu, T. Zortelan, M. Mocanu, C. Schuster, C. Opran.

We are in the decade in which project management is more than "wave of the future"; in recent years has become a necessity. It speaks more often about a "project society" within the meaning of society that are frequently used to carry out projects and programs of medium and high complexity; about the need for a culture project to pass through Romanian society from the central and local public institutions, the private sector, to small communities.

Each organisation is facing continuous problems, needs and opportunities. Problems like low operational efficiency, the need for additional space for offices and opportunities as the penetration on new markets are only few of the endless situations that the management of an organisation or of a company is facing.

The achievement of these solutions entails certain changes in the organisation. Projects usually have to do with carrying out this change, with someone always being responsible for the successful completion of each project. The project manager is the main agent of change and the guide directing him is the project management process.

The Project Management Institute (PMI) in the USA defines the project management as "an application ok knowledge, skills, instruments and techniques on different activities for the achievement of the project's requirements". Project management is fulfilled by applying and integrating the initiation, planning, execution, monitoring, control and closing processes. (James P. Lewis, 2007)

The project management aims at a better usage of the existing resources, by ensuring that the workflow is running both horizontally and vertically within the company. This approach of course does not eliminate the flow of documents vertically, but it only implies a better

\footnotetext{
${ }^{1}$ Lucian Blaga University of Sibiu, Romania, e-mail: diana.ranf@roger-univ.ro
} 
communication at the horizontal level in order to make sure that the objectives are met consistently throughout the entire organisation. The line managers are responsible for the vertical workflow, while the project managers are responsible for the horizontal workflow, their effort consisting of providing good communication and coordination among the horizontal activities of the vertical lines. (Kerzner, Harold, 2005)

The following figure illustrates the organisation of a company, with the top management and environmental structures, the supervisors and finally the workers. The figure also illustrates the functional organisation between the company's working units.

If the management and functional levels overlap, we notice that companies are made up of small operating islands that usually refuse to communicate with each other. The project manager's responsibility is to ensure a good communication between these "islands", created for common purposes and objectives.

Based on the figure below, Harold Kerzner defines the project management as the planning, organisation, management and control of an organisation's resources to reach an established short-term objective for the pursue of specific purposes and goals. Project management uses the systemic approach of management, so that the personnel employed on functions (the vertical hierarchy) is involved in specific projects (the horizontal hierarchy). (Kerzner, Harold, 2005)

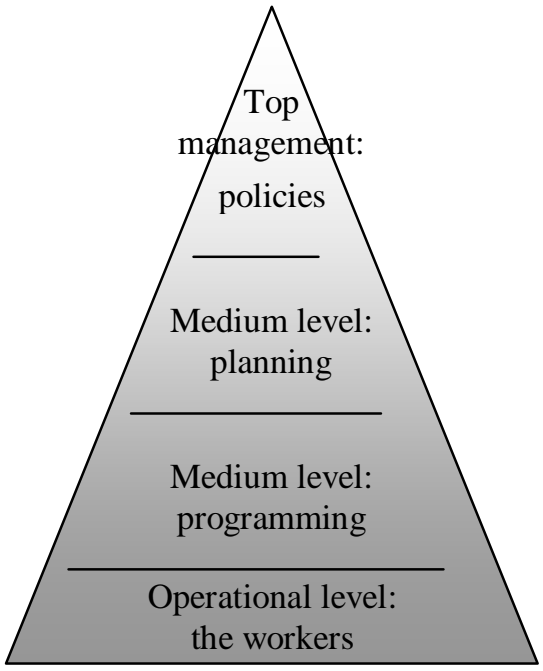

MANAGEMENT

LEVELS

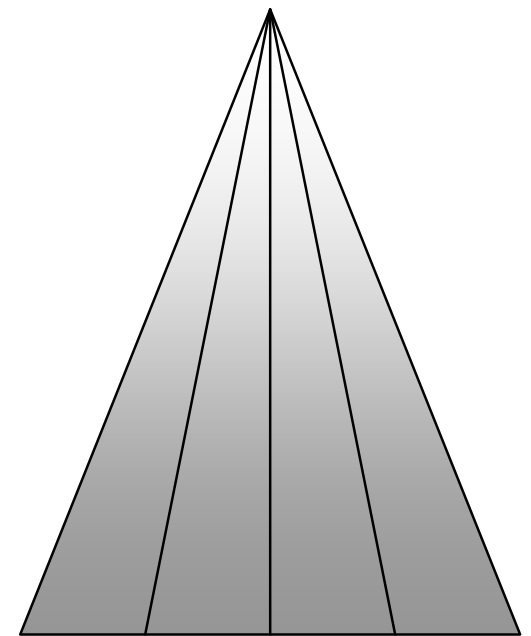

FUNCTIONAL LEVELS: STRUCTURING ON DEPARTMENTS

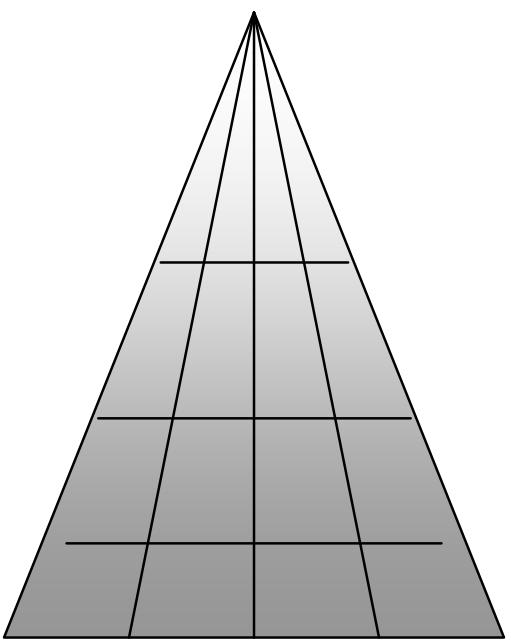

STARTEGIC ISLANDS (MANAGEMENT CENTRES)

Fig. no. 1 - Structural and functional organisation of a company

Starting from the above mentioned triple constraint of the project, i.e. the constraint of duration, time and purpose we can represent the project management, adding the fact that a very good relationship with the clients should be kept. (fig. no. 2)

From the technical point of view, the management of a project by meeting the terms, budget and technology without involving the customers is possible, but with the risk of affecting the future results of the business. 


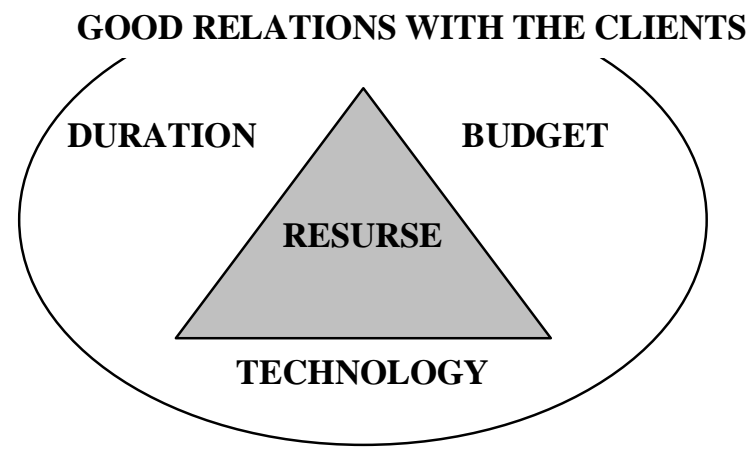

Fig. no. 2 - The representation of projects' management

\section{Project management - a ,strategic power"?}

The beginning of the $21^{\text {st }}$ century is characterised by a rapid pace of change and the changes occur through the projects. Regardless of the environment the organisation operates in, be it public, private, non-profit, whether it is a large or small organisation, it has to adapt: either through the implementation of some changes, or at least to keep up with the peers in the field. (Verzuh, Eric, 2003)

The rapid pace of change may induce a state of uncertainty within organisations. The project management discipline may reduce the risk of installing such uncertainties. This discipline uses techniques already established for the selection, planning and execution of projects, costs reduction, resources programming and increasing the quality of results.

The effective execution of projects has always been considered important. Budget, deadlines overruns or wrong delivery of products has never been accepted. However, in the past, the project management was regarded as a tactical "power".

Given the fact that companies are increasingly managed through projects, the managers' ability to manage projects consistently and competently, being considered a tactical competence, has turned into a strategic competence. The companies that recognise the project management as a strategic competence, an ability that offers them the competitive advantage regard this discipline as a process that can be constantly defined and improved.

Thus, this "strategic power" comes from the competitive advantage that influences the strategy of a company. In the best case, it is such a dominant power that it can prevent competitors from entering into the market.

In the past, a series of strategic advantages were:

- Scale economies allowed manufacturers to increase production with the lowest costs possible; the pioneer of this idea was Henry Ford, cultivated throughout the $20^{\text {th }}$ century;

- The establishment of some large distribution networks that provide channels for delivering products to customers;

- The specialization and organisation on processes enabled organisations to make better products, at lower costs.

But the project management is not a strategic advantage for all companies because not every organisation has a project-based management. For example, it would be difficult for retail stores to focus on the project management as a competitive advantage.

If some of the following factors can be encountered in an organisation, we can state that it can consider the project management as a strategic management. These can be applied for the entire organisation (if it is managed on projects), or only for a department (office) of the project management:

- The project management is a tactical skill for the organisation; 
- The company devotes a great part of its budget or incomes to invest in projects;

- The industry within which the company operates is lead by projects; an industry may be considered a project (for example in the constructions, information technology fields etc);

- The company runs several independent projects at the same time; the independent projects unrelated to each other may be a challenge for managers;

- The company has important development and growth objectives; the growth means change, and change is implemented through projects;

- The organisation runs important projects, whose failure would cripple the company; when one has ongoing strategic projects, the ability to manage them becomes a "strategic power".

For the organisations in which most of these factors can be found, the project management is more a strategic force, it is a capability that can fundamentally change the ability to manage the company.

The ability to reduce the risk makes the project management a strategic component since it brings changes into the risk versus opportunity equation. Project management changes the old financial rule where getting high profits assumes high risks. For this reason, this advantage enables organisations to take part to "high-stakes games" and to have more consistent winnings.

Therefore, the project management may be considered a strategic power because it gives the organisation an advantage over the competitors, makes a stronger competitor. This advantage has the effect of increased performances of the project, more precise costs and programmes, and also the increased ability to recognise problems early. Moreover, the ability to manage a project portfolio, to select the projects whose results will best meet the requirements of the organisation is improved. The strategic power is an ability that gives a competitive advantage.

These companies focus on three elements:

A. A rigorous portfolio of the management processes in order to choose the correct projects the company will invest in and to supervise the projects that are in progress.

B. A consistent number of methods used in the project management, so that each project uses the proper planning and management instruments of the project.

C. A project management department responsible for maintaining and improving this portfolio of management processes, as well as of the methods used within the projects.

The strategic importance of project management is underlined by Bârgăoan Alina, in an article stating that the relationship - until recently theoretical - between development and project management explicitly sets the basis for the multi-annual development strategies of several countries. Governments give a particular importance to the project management, especially in areas considered as of strategic importance such as constructions, computer science industry, aerospace, biochemical products industry, mining industry, environment. (Bârgăoan, Alina, 2006)

\section{A new vision on project management}

According to the traditional opinion of project management, when a project manager completes a project and meets the triple constraint of time, cost and performance, the project is considered a success. Nowadays, in the eyes of the customer or the parent company or sponsor, if at the end, the project does not have its anticipated value, it is considered a failure.

The authors, Kerzner, H., Saladis, F.P., in „Value driven management project”, we are being pointed out that, due to the serious economic changes, in an increasingly competitive global environment, managers begin to focus more on business. Projects should now be regarded from a strategic perspective, in the context of a business or enterprise that should provide value both to the customer and to the parent corporation.

The traditional project management works well when the project's direction is clearly understood, the scope is well defined and all interested parties agree upon the objectives and expectations, the risks have been evaluated and, of course, the success probability is considered very high. As compared to this traditional approach, companies that wish to be innovative and to 
become market leaders, rather than followers of the market, should develop projects that are based on "fluffy" objectives, on optimism, and the willingness to risk and virtually not follow a specific set of selection criteria.

Projects have become larger and very complex and they might require a technical progress in order to be successful. Moreover, the risks associated to achieving this objective may be very important, there is no guarantee that the project will be successful and that the completion of the project will have the expected value.

Today's projects are not necessarily as well-defined and understood as the past projects. The global economy, increased costs and competition have made many companies take higher risks to achieve their business objectives. As a result, traditional theories of project management may not work well if they are applied to these new types of projects. A change is required in how projects are managed and in the way decisions are taken.

After more than 40 years of analysis, learned lessons, volumes of documents of the best practices, companies have realised that the well-defined and effectively-implemented project management methodology is very beneficial to the growth and stability of an organisation. The basic principles of project management can be applied to all parts of a business.

Project management, as a discipline, affects all parts of a business and is present at all levels of management. Every functional unit generally manages the projects that support the higher level business objectives and the line managers or the functional managers are trained with project management instruments for managing projects that are exclusively within their functional area. Although the project management has been regarded as a profession, only during the last decade the companies gave project managers the possibility to make a career out of their profession.

Table no. 1

Changing the vision on project management

\begin{tabular}{|c|c|c|c|}
\hline & HISTORICAL VISION & 1990 & TODAY \\
\hline $\begin{array}{l}\text { The role and } \\
\text { responsibility of the } \\
\text { project manager }\end{array}$ & $\begin{array}{l}\text { Monitors and controls the } \\
\text { execution of the project }\end{array}$ & $\begin{array}{l}\text { Plans the execution of the } \\
\text { project }\end{array}$ & $\begin{array}{l}\text { Develops strategies and } \\
\text { selects the entries in the } \\
\text { project }\end{array}$ \\
\hline $\begin{array}{c}\text { When he came, ,on } \\
\text { board" }\end{array}$ & $\begin{array}{l}\text { After winning the contract } \\
\text { or at the end of initiation }\end{array}$ & $\begin{array}{l}\text { During the preparation of } \\
\text { the project proposal }\end{array}$ & $\begin{array}{l}\text { During the development of } \\
\text { the concept and the entry in } \\
\text { the field of decisions on the } \\
\text { offer }\end{array}$ \\
\hline Necessary knowledge & $\begin{array}{l}\text { Technological knowledge } \\
\text { (technology was a priority) }\end{array}$ & $\begin{array}{l}\text { Technical knowledge, in } \\
\text { general, but also a series of } \\
\text { knowledge of "business" }\end{array}$ & $\begin{array}{l}\text { Business knowledge in } \\
\text { general and a series of } \\
\text { technical knowledge }\end{array}$ \\
\hline Customers' expectations & Delivery is important & Delivery is important & Business solutions \\
\hline The definition of success & $\begin{array}{l}\text { Compliance with the triple } \\
\text { constraint of the project }\end{array}$ & $\begin{array}{l}\text { Compliance with the triple } \\
\text { constraint of the project }\end{array}$ & $\begin{array}{c}\text { Multiple success criteria } \\
\text { (both of the project and in } \\
\text { business) }\end{array}$ \\
\hline
\end{tabular}

Capturing the best practices has become a business necessity. The best office practices are regarded as a competitive weapon and it may create significant advantages in presenting the price offer. From the historical point of view, managers were expected to acquire the best practices, but only those related to the project management.

Nowadays, since project managers are currently regarded also as business managers, they must also pay attention to the best practices in business.

In the past, project managers were regarded as organisational resources, task-oriented and who did not necessarily had too thorough knowledge on business or strategic issues, but had exceptional skills in developing and executing the plans. It was considered a common business practice to hire people who are responsible with planning or estimation, developed plans which 
were later assigned to a project manager who would execute them. Usually, project managers have not been "brought on board" of the project at the beginning of the project, but were included in the project after most part of the planning was completed. (Kerzner, H., Saladis, F.P., 2010)

Gradually, by accumulating experience, project managers improved their planning abilities. Nowadays, the project managers get more actively involved in the business decisions. Among the inputs of a project manager there are:

Establishing the project's objectives at the level of technical components and at the business level;

A development strategy that would connect the project's objectives with the organisational objectives;

- The selection of projects, as part of the management portfolio;

- Prioritization of projects, also as a part of the management portfolio ;

- Decisions on the organisation's offer.

For many years, the functions of project managers were assigned to engineers, because of the technical knowledge they possessed. This concept emerged from the perspective of customers. They believed that the project managers had to have a thorough knowledge of the product, technical skills, rather than abilities to manage the teams and coordinate the results.

But because projects have increased both in size and in complexity, it has become obvious that project managers were challenged to expand this technology-led authority in all aspects related to the project along with the daily activities of the project. Moreover, as project managers, they spent more time improving the project management functions, such as monitoring and evaluating the project's performances and had less time at their disposal to give importance to the technical aspects of their own functional disciplines.

As expected, in today's business environment, many project managers have more than basic technical knowledge, or as the author calls them "understanding of technology", rather than a "control of technology". At the same time, the project manager's knowledge of business operations have increased considerably, reaching the point where the project managers are trustworthy in taking the important business decisions. Project managers are now regarded as business managers, that orientation towards tasks belonging to the past now.

In the past, customers have paid contractors for their ability to deliver the goods to destination. If a new delivery was required, there was no guarantee that the first contractor would show interest to this regard. Customers were interested in the final result and not in the means to reach this final result. A series of partnerships also arose, but the customer wanted to keep as many suppliers involved, consequently stimulating competition.

As resulting from the table above, the success of the project used to be measured based on the compliance with the triple constraint of time, cost and performance. This used to be considered a reasonable definition of a project's success if its purpose is simply the development of a new product. But then the question rises: what happens if the product is part of a bigger effort, what would a programme in which the product has to be commercialized and sold as part of a strategic effort be? If the project was completed in compliance with the parameters of the triple constraint and the company discovers that there is a small demand for that product, can the project be considered a success or a failure?

In the past, the difference between the success of the project and of the programme (or of the business) was made. It was possible for a project to be successful, but the programme was considered a failure. Nowadays, the definition of success has business components, such as the ability to sell the product, the ability to satisfy a market need. Slowly, but surely, other business elements are included in the definition of success, which will align each project to the company's strategic objectives. This will encourage enterprises to develop a common definition of success that would apply both to the project and to the programme. In the future, the success of the project and of the programme is expected to be connected and interdependent. 
Table no. 2

\section{Other changes regarding the project management vision}

\begin{tabular}{|c|c|c|c|}
\hline & HISTORICAL VISION & 1990 & TODAY \\
\hline $\begin{array}{c}\text { The success of the project } \\
\text { / programme }\end{array}$ & $\begin{array}{c}\text { The success of the project } \\
\text { is critical }\end{array}$ & $\begin{array}{c}\text { The success of the } \\
\text { programme is critical }\end{array}$ & $\begin{array}{c}\text { The successes of projects } \\
\text { and programmes must be } \\
\text { integrated }\end{array}$ \\
\hline $\begin{array}{c}\text { The limits of the project } \\
\text { management }\end{array}$ & $\begin{array}{c}\text { Organisational project } \\
\text { management }\end{array}$ & $\begin{array}{c}\text { National project } \\
\text { management }\end{array}$ & $\begin{array}{c}\text { The global project } \\
\text { management is essential for } \\
\text { the future }\end{array}$ \\
\hline $\begin{array}{c}\text { The management } \\
\text { portfolio }\end{array}$ & $\begin{array}{c}\text { Kept strictly secret by top } \\
\text { level management }\end{array}$ & $\begin{array}{c}\text { Most part at the higher } \\
\text { level, but a part also at the } \\
\text { middle level }\end{array}$ & $\begin{array}{c}\text { Considerable involvement } \\
\text { of project managers and } \\
\text { project management office }\end{array}$ \\
\hline
\end{tabular}

In the past, the project management has had some significant limitations regarding its usage. In many companies, it was common for the project management to be restricted only to the use within the departments that were managed through the project or based on a project, such as the information technology. All the other departments were mostly free to use their own approaches and methods to meet the objectives. Only those departments that were considered project-based have used a formal project management methodology.

Each division of a company could decide independently whether to use or not a project management methodology. Faced with this challenge, managers stated that it was almost impossible for an entire organisation to agree with the implementation of the project management, especially with accepting a common EPM (Enterprise Project Management) methodology to be used by all business components. EPM systems are usually rigid processes designed around policies and procedures and that can work effectively if the working relation is well-defined.( Kerzner, H., Saladis, F.P., 2010)

Nowadays, the project management has become a factor present at all levels, in all divisions of many companies, and this includes the global business environment. Some companies consider that this globalisation of the project management methodology is essential for the survival of the company. Multinationals now manage all projects with a unique EPM methodology. This unique methodology is used to plan and execute projects for all customers any type of product and for the entire project or life cycle of the product.

\section{Conclusions}

Under the current economic context, flexible organisational structures are required within organisations that would enable the rapid reaction to environment, market-orientation, that would assimilate and process new information, be innovative and find new solutions. Managerial concepts should be developed to enable the employees' personal involvement and taking some personal, individual responsibility. Therefore, the project management, as part of a modern organisational management concept, may be the first step towards the employees' affirmation in the spirit of cooperation and openness to new.

The article approaches the change of vision on management in the last decades. This new vision considers project managers as increasingly dynamic people who are getting involved more actively in the business decisions; under these circumstances, the technical knowledge lose importance and the knowledge in business gains importance.

If the success of the project used to be traditionally measured based on the compliance with the triple constraint of time, cost and performance, nowadays, the definition of success has elements of business, such as the ability to sell the product, the ability to satisfy a market need. Slowly, but surely, elements of business are included in the definition of success which will align each project to the company's strategic objectives. 
In the current economic climate, organizations need more flexible organizational structure to enable rapid reaction to the environment, market orientation, to assimilate and process new information in time, to be innovative and find new solutions. Project management, as part of a modern concept of organizational management, may be a first step towards the affirmation of the spirit of cooperation and openness employees to new.

Romania, as a member of the European Union should work towards stimulating economic growth potential, maintain and achieve high growth rates. In order to achieve these objectives should be considered as project management awareness and promoting at micro and macro economic approach, professionalism in the field, creating a true culture of projects in regions, cities, public and private institutions.

\section{Acknowledgement}

Researches carried out within the framework of the project POSDRU/6/1.5/S/26, co financed from the Social European Fund by means of the Sectorial Operational Fund Programme „The Development of Human Resources” 2007-2013.

\section{References}

1. Bârgăoan A., 2006. Project management - a prerequisite for macroeconomic development, Review of Management and Marketing, No. 3, Economic Publishing House, pp. 45-50

2. Lewis J. P., 2007. Project Management Fundamentals, Amacom Publishing House, USA

3. Kerzner H., 2005. Project management - a system approach to planning, scheduling and controlling, Italian edition by Ulrico Hoelipi Editore, Milano

4. Kerzner H., Saladis F.P., 2010. Value-driven project management, John Wiley\&Sons Publishing House, USA

5. Lewis P. J., 2010. Project Planning, Scheduling and Control, McGraw Hill Publishing House, USA

6. Verzuh E., 2003. The Portable MBA in Project Management, John Wiley\&Sons Publishing House, USA 